\title{
Recuperação de Prata Metálica de Chapas de Raio-X
}

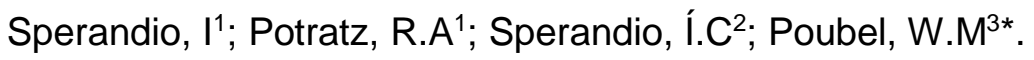 \\ 1 Graduação em Engenharia Química, Universidade Federal do Espírito Santo, Alegre, ES, Brasil. \\ 2 Graduação em Engenharia Ambiental, Empresa Brasileira de Ensino Pesquisa e Extensão, Vitória, ES, Brasil. \\ 3 Departamento de Engenharia Rural, Universidade Federal do Espírito Santo, Alegre, ES, Brasil. \\ *e-mail: willian.poubel@ufes.br
}

\begin{abstract}
Resumo
No mundo globalizado, a crescente preocupação com os índices de desenvolvimento humano e com a qualidade de vida das pessoas provocou a maior utilização em práticas medicinais com utilização de filmes radiográficos. Os raios $\mathrm{X}$ são usados para a análise de tecidos humanos e animal. Todavia, apesar dessa técnica representar um grande avanço científico, ela tem sido executada de maneira incorreta quando se diz respeito a estocagem e descarte desses exames após sua utilização hospitalar. Tendo em vista que o descarte incorreto ocorre em grande escala, o presente trabalho apresenta metodologia para que haja a extração da prata metálica, um metal pesado, presente no filme e consequentemente a diminuição dos impactos socioambientais causados, objetivando ao máximo respeitar os direitos humanos e a harmonia entre os setores social, econômico e ambiental.
\end{abstract}

\begin{abstract}
On globalized world the growing preoccupation with human development index and with life's quality made the increased use in medicinal practice with radiographic films. The $x$-ray is used to analyze human and animal tissue. Although this technique represents a huge scientific breakthrough, its' been executed in wrong way when it concerns to storage and disposal of these exams after its utilization. In view of wrong disposal occurs in big scale this paper presents methods so there is the extraction of metallic silver, a heavy metal present in the film, and consequently decreases of environmental impacts. Its aims utmost respect human rights and harmony between social, economic and environmental factors.
\end{abstract}

Keywords (Palavras chaves): raio X, prata metálica, filmes radiográficos.

\section{Introdução}

A sociedade moderna é reflexo dos avanços técnicocientíficos em diversos setores do conhecimento obtidos após anos de estudos que visam o aumento da qualidade de vida da humanidade. Um desses avanços remonta à descoberta do raio $\mathrm{X}$ em 1895 pelo físico alemão Wilhelm Conrad Roentgen em seu laboratório, onde também ocorreu a primeira radiografia que se tem registro histórico. [1]

Atualmente, os raio $X$ são utilizados em larga escala na área medicinal, para ocorrer a análise e detecção de fraturas ósseas, uma vez que as ondas eletromagnéticas não conseguem atravessar os mesmos, pois esses possuem alta densidade, sendo assim, aqueles raios capazes de transpassar a estrutura em questão projetam uma imagem no filme de raio $X$. Após o processamento desse filme é formado o nitrato de prata. [2]

O filme é composto por quatro camadas, sendo a primeira formada por uma base plástica de acetato, que serve como suporte para a solução. A segunda, é formada por uma fina camada de adesivo, com a responsabilidade de fixar o metal na placa. A terceira camada é a emulsão, composta de cristais halogenados de prata em uma matriz de gelatina, essa camada fica em ambos os lados e após ser atingido pelos raios $X$, são sensibilizados e reduzidos a prata negra, metálica, onde ocorre a formação da imagem. A quarta e última camada é uma gelatina transparente, 


\section{SEMANA DE ENGENHARIA QUÍMICA UFES}

utilizada com o intuito de proteger as camadas anteriores. [3]

Grande parte dessas imagens radiográficas é devolvida aos pacientes. Entretanto, outra parcela considerável do filme de raio $X$ fica armazenada nos hospitais $e$ após algum período são descartadas, algumas vezes de maneira incorreta, e o que pode provocar grandes danos ambientais, por exemplo, o efeito de bioacumulação, isto é, os metais presentes nessa estrutura quando degradados podem ser absorvidos pelos organismos vivos primários considerando a cadeia alimentar, e através destes chegarem ao topo da cadeia, o ser humano. No homem esses metais poderão estar em altas concentrações e provocar danos à saúde, por exemplo, problemas psíquicos. [4]

No Brasil existe uma legislação vigente que trata do descarte correto dos materiais gerados com este exame, a Resolução no 358/05 do Conselho Nacional do Meio Ambiente (CONAMA), onde os efluentes de processadores de imagem são considerados do grupo $B$, por apresentarem substâncias químicas que podem causar risco à saúde pública ou ao ambiente. Devido ao aumento da utilização deste exame, os problemas de destinação se tornam mais tênues, sendo assim, é necessário um processamento eficaz para se recuperar o máximo possível dos componentes, minimizando assim os impactos ambientais. [3]

Visando o reaproveitamento dos compostos constituintes do filme de raio $X$ para evitar sérios danos, foi desenvolvida uma hipótese de extração da prata metálica presente, juntamente com outras substâncias subsequentes, através de métodos descritos posteriormente.

A prata, é um composto de fórmula molecular $\mathrm{Ag}$, com massa atômica 107,8682, sendo um metal de transição sólido a temperatura ambiente, dúctil, bom condutor de energia e calor, e ainda muito utilizado na indústria, como por exemplo na fabricação de ligas odontológicas, na fabricação de explosivos, produção de joias, além do mais, é o composto essencial na fabricação de fotografias convencionais, entre outros usos. [5]
Para ocorrer a minimização desses impactos provocados pelo descarte incorreto devem ser feitos estudos técnico científico que visem através das metodologias adequadas essa redução. Todavia serão dissertados ao decorrer do trabalho alternativas que possam servir como solução para essa problemática. Ademais, apesar de existirem indústrias que já realizam esse tipo de trabalho, não há fomento para que tais parâmetros sejam pesquisados. Em consequência disso, muitas fábricas ainda continuam usando procedimentos não muito eficazes se analisados de forma geral em todos os conceitos, como rendimento, custo energético e de produção, dentre outros. Todavia devem ser aplicadas medidas de universalização da informação para que a população saiba dos riscos envolvidos e problemas futuros causados pelos maus hábitos.

\section{Materiais e Métodos}

- Chapas de raio X;

- Água destilada;

- Hidróxido de Sódio 0,1M;

- Bomba de vácuo;

- Vidro relógio;

- Becker (1 e 2L);

- Filtro de papel;

- Recipiente de plástico;

- Kitassato;

- Mufla;

- Estufa;

Foi retirado a camada de revestimento das chapas de raio $\mathrm{X}$ com o auxílio de hidróxido de sódio dissolvido em água destilada na proporção de $2 \mathrm{~L}$ de reagente para cada $1,5 \mathrm{Kg}$ de raio $\mathrm{X}$.

O processo de retirada foi realizado da seguinte maneira:

Primeiramente foi feita a solução de hidróxido de sódio na proporção necessária para que não houvesse supersaturação da solução. Em seguida foram colocadas submersas em solução as chapas de raio $X$. Foi obtida uma mistura homogênea de coloração escura, posteriormente submetida a filtração a vácuo. 
De acordo com Vogel [2], a prata que recobre a película de acetato é precipitada como óxido de prata, um pó fino, de coloração preta ou marrom.

O produto obtido da filtração foi então separado em vidros relógios e a solução reservada em recipientes de vidro para posterior análise. Sendo a amostra do vidro relógio classificada como $\mathrm{Ag}_{2} \mathrm{O}$.

Processos como exposição à fonte de calor ou luz permite que tenhamos a partir do Óxido de prata obtido a prata metálica, objeto de interesse.

O óxido de prata obtido foi exposto a uma fonte de calor, mufla, tendo como produto prata metálica, o que foi comprovado através de testes físicos.

\section{Resultados e Discussão}

De acordo com a metodologia acima, retirou-se a camada de revestimento das chapas de raio-X com o auxílio de hidróxido de sódio e água. Determinou-se a média dos volumes gastos no processo de acordo com a equação (1), sendo necessário $2 \mathrm{~L}$ de reagentes a cada $1,5 \mathrm{Kg}$ de chapas de raio- $\mathrm{X}$ :

$$
V m=\frac{\left(V_{1}+V_{2}+\cdots+V n\right)}{n}
$$

Após a completa retirada da película de revestimento as placas foram lavadas com água e secas em estufa. Obteve-se através deste processo uma solução homogênea de coloração escura contendo óxido de prata, mostrada na figura 1. A solução apresenta coloração escura devido à reação de redução da prata, já que o recipiente se encontra exposto a luz.

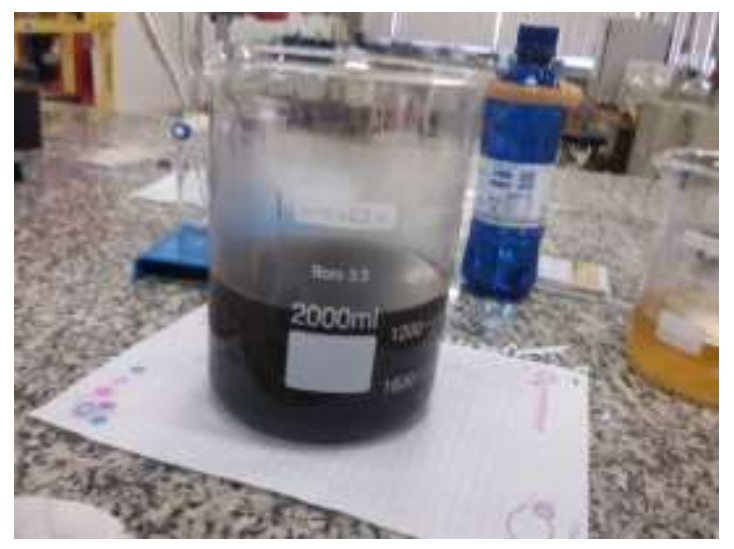

Figura 1: Imagem da solução obtida após a exposição das chapas de raio $\mathrm{X}$ com o hipoclorito de sódio.
Filtrou-se a vácuo a solução obtida, separando então o óxido de prata precipitado do sobrenadante, processo mostrado na figura 2.

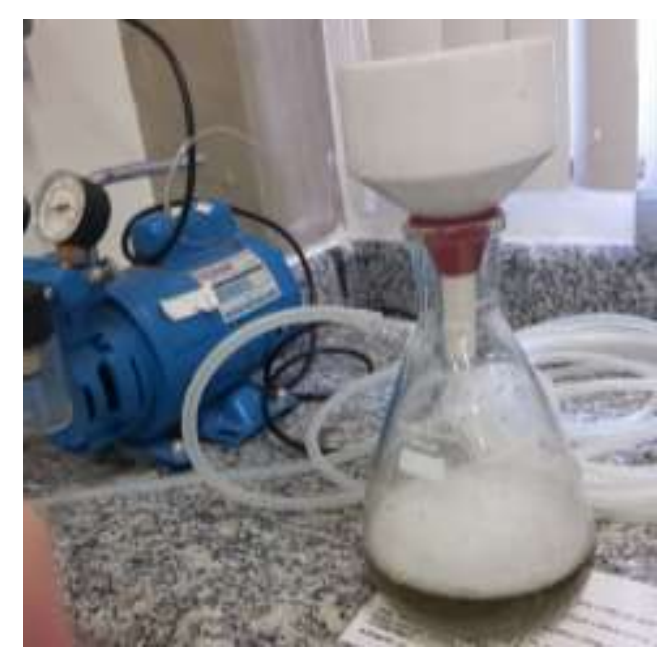

Figura 2: Imagem do processo de filtração a vácuo da solução obtida.

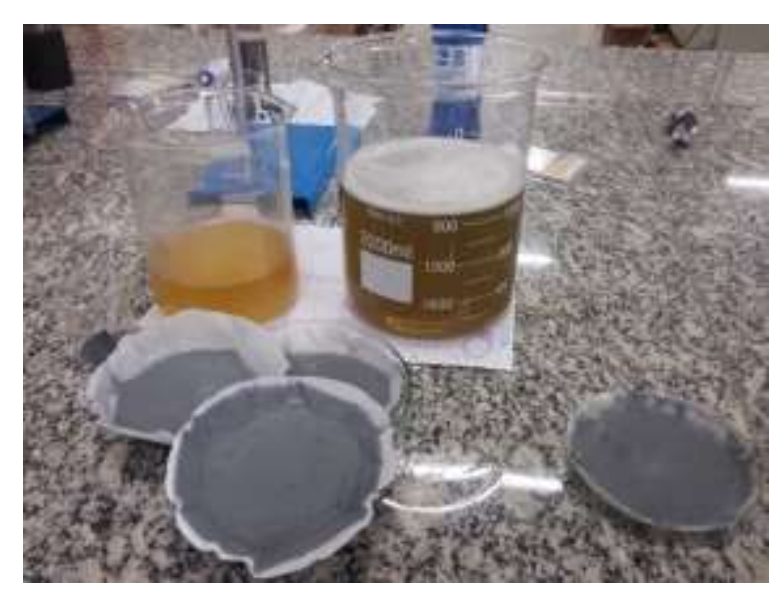

Figura 3: Imagem dos produtos obtidos na filtração.

Colocou-se o óxido de prata presente no vidro relógio em um cadinho e submeteu-o a calor com o auxílio da mufla em tempo e temperatura necessária para a fusão da prata metálica.

Obteve-se assim o produto principal prata metálica e o sobrenadante. Reservou-se o sobrenadante para análises e estudo de possíveis usos.

\section{Conclusão}

Foi obtido um produto de baixo custo, alto rendimento e com um valor socioambiental de extrema relevância, o qual foi classificado como prata metálica a ser purificada. É necessário a aplicação de experimentos complementares para a devida purificação. A aplicação 


\section{SEMANA DE ENGENHARIA QUÍMICA UFES}

do estudo se torna economicamente viável e ecologicamente sustentável em escalas industriais.

Os resultados obtidos neste trabalho deverão contribuir sobremaneira para o manejo adequado de rejeitos provenientes de processos radiográficos. A aplicação dos resultados irá contribuir sem dúvidas, para a diminuição do impacto ambiental negativo gerado pelo despejo descontrolado de materiais radiográficos em diferentes sistemas públicos, bem como, agregar valor ao produto gerado em função da recuperação da prata.

\section{Referências}

[1] OLIVEIRA, Ralph Santos; LEÃO, Ana Maria dos Anjos Carneiro. História da radiofarmácia e as implicações da emenda constitucional. Disponível em:<http://www.scielo.br/pdf/rbcf/v44n3/a06v44n3.pdf >. Acesso em 08 de out. 2015.

[2] CAVALHEIRO, Maria Cecília H.T; MION, Caroline Franceschini; LIPORINI, Amanda Quatrocchio; LIBARDI, Marina Gandini Garcia. Tratamento químico e reciclagem de chapas de raio- $X$. Disponível $\quad$ em:<http://www.sga.usp.br/wpcontent/uploads/12.pdf>. Acesso em 06 de out. 2015.
[3] BAMPI, Janaina; SECHI, Makeli; GONÇALVES, Cátia Viviane. Resíduos de filmes radiológicos. Vamos pensar sobre isso? Disponível em:< https://www.univates.br/tecnicos/media/artigos/artigo janaina_bampi.pdf>. Acesso em 07 de out. 2015.

[4] AZEVEDO, Ingridy Raynara da Silva; OLIVEIRA, Uilca Sadrelly do Prado. A busca pela prata dos filmes radiográficos: Química a serviço do meio ambiente. Disponível em:< http://www.editorarealize.com.br/revistas/eniduepb/tra balhos/Modalidade_4datahora_27_09_2013_22_31_ 42_idinscrito_1096_a932a8f0d843da2e310ffe8a8f9fe f44.pdf> Acesso em: 10 de out. 2015.

[5] SHAIKHZADEH, Badi M. Prata, Ouro e Platina. Disponível em:< http://www.eletrica.ufpr.br/piazza/materiais/BadiShaik hzadeh.pdf>. Acesso em 06 de out. 2015. 